\title{
Article \\ The North Equatorial Countercurrent East of the Dateline, Its Variations and Its Relationship to the El Niño Event
}

\author{
Yusuf Jati Wijaya ${ }^{1,2} \mathbb{D}$, Ulung Jantama Wisha ${ }^{1,3} \mathbb{D}$ and Yukiharu Hisaki ${ }^{1, *(\mathbb{D})}$ \\ 1 Department of Physiscs and Earth Sciences, University of the Ryukyus, Senbaru 1, Nishihara-cho, \\ Okinawa 903-0213, Japan; yusufjatiwijaya@gmail.com (Y.J.W.); ulungjantama@kkp.go.id (U.J.W.) \\ 2 Department of Oceanography, Faculty of Fisheries and Marine Science, Diponegoro University, \\ Semarang 50275, Jawa Tengah, Indonesia \\ 3 Research Institute for Coastal Resources and Vulnerability, Ministry of Marine Affairs and Fisheries, Jl. Raya \\ Padang-Painan KM. 16, Bungus, Padang 25245, Sumatera Barat, Indonesia \\ * Correspondence: hisaki@sci.u-ryukyu.ac.jp; Tel.: +81-98-895-8515
}

check for updates

Citation: Wijaya, Y.J.; Wisha, U.J.; Hisaki, Y. The North Equatorial Countercurrent East of the Dateline, Its Variations and Its Relationship to the El Niño Event. J. Mar. Sci. Eng. 2021, 9, 1041. https://doi.org/ 10.3390/jmse9101041

Academic Editor: Francisco Pastor

Received: 31 August 2021

Accepted: 20 September 2021

Published: 22 September 2021

Publisher's Note: MDPI stays neutral with regard to jurisdictional claims in published maps and institutional affiliations.

Copyright: (c) 2021 by the authors. Licensee MDPI, Basel, Switzerland. This article is an open access article distributed under the terms and conditions of the Creative Commons Attribution (CC BY) license (https:// creativecommons.org/licenses/by/ $4.0 /)$.

\begin{abstract}
Using forty years (1978-2017) of Ocean Reanalysis System 4 (ORAS4) dataset, the purpose of this study is to investigate the fluctuation of the North Equatorial Countercurrent (NECC) to the east of the dateline in relation to the presence of three kinds of El Niño events. From spring (MAM) through summer (JJA), we found that the NECC was stronger during the Eastern Pacific El Niño (EP El Niño) and the MIX El Niño than during the Central Pacific El Niño (CP El Niño). When it comes to winter (DJF), on the other hand, the NECC was stronger during the CP and MIX El Niño and weaker during the EP El Niño. This NECC variability was affected by the fluctuations of thermocline depth near the equatorial Pacific. Moreover, we also found that the seasonal southward shift of the NECC occurred between winter and spring, but the shift was absent during the CP and MIX El Niño events. This meridional shift was strongly affected by the local wind stress.
\end{abstract}

Keywords: El Niño; the NECC; east of the dateline; Pacific Ocean

\section{Introduction}

Situated in the low-latitude North Pacific Gyre, the North Equatorial Countercurrent (NECC) is an eastward-flowing surface current. Its position is centered at the latitude of $\sim 5^{\circ} \mathrm{N}$ to the west of the dateline [1,2] and further eastward, shifting toward $\sim 7^{\circ} \mathrm{N}$ in the eastern part of the Pacific [3,4]. The NECC plays a pivotal role in the global atmospheric circulation since it carries on average 20 to $30 \mathrm{~Sv}$ ( $1 \mathrm{~Sv}$ is equal to $10^{6} \mathrm{~m}^{3} \mathrm{~s}^{-1}$ ) of surface water of warm pool from the western to the eastern Pacific Ocean $[3,5,6]$. The NECC is closely related to the Intertropical Convergence Zone, which is crucial to the distribution of nutrients in the tropical Pacific Ocean [7].

The dynamics of the NECC are strictly tied to the El Niño-Southern Oscillation (ENSO) event according to the work of previous studies [1,2,8-12]. This is not surprising, as the NECC is located at the place where the ENSO event is evoked. Satellite and ocean simulation observations have suggested a strong magnitude and a southerly path of the NECC west of the dateline during El Niño, whereas its position shifts to the north and is weakened in La Niña $[2,9,11]$. The westerly wind associated with Rossby wave variations is highly responsible for those occurrences. East of the dateline, El Niño's effect on the NECC is determined by the type of El Niño itself. Previous observations have separated El Niño events into two different classifications depending on the anomalous pattern of the sea surface temperature (SST) throughout the Pacific Ocean, namely the central Pacific (CP) El Niño and the eastern Pacific (EP) El Niño [13-17]. Some researchers have proposed that EP El Niño's influence on the NECC was greater than that of the CP El Niño east of the dateline $[8,10,12]$. During the EP El Niño, the NECC tends to strengthen and migrate southward from the phase of development to the mature phase because of the shifting of the curl of wind stress distribution, which leads to changes in thermocline variability. 
To date, the NECC variations east of the dateline are still an interesting topic to observe, notably their varied reactions to the EP and CP types of El Niño events throughout the phases of developing and maturing. Thus, in this paper, we propose an investigation of the NECC variations to the east of the dateline using the Empirical Orthogonal Function (EOF) approach as the analysis technique to provide a new suggestion or enhance the ideas of previous research. We used the zonal component of the surface current from reanalysis data for 40 years of observations to investigate their spatial and temporal variations, especially during summer and winter, which are often referred to as the stages of developing and maturing from El Niño, respectively $[18,19]$. This paper is arranged in the following way: Section 2 explained the materials and the methods used; Section 3 contained a summary of the experimental outcomes; finally, in Sections 4 and 5, we conclude the paper with a discussion and conclusion, respectively.

\section{Materials and Methods}

The Ocean Reanalysis System 4 (ORAS4) dataset retrieved from European Centre for Medium-Range Weather Forecasts (ECMWF) was used in this work, which spans 40 years (1978-2017) and has a 1-degree grid resolution. These data are monthly averages of the zonal and meridional components of the ocean surface current, extending from $4.5^{\circ} \mathrm{N}$ to $11.5^{\circ} \mathrm{N}$ and $178.5^{\circ} \mathrm{W}$ to $70.5^{\circ} \mathrm{W}$. The ORAS4 dataset is freely available from 1958 to 2017 and covers the entirety of the Earth. By replacing its predecessor, ORAS3, various recent features and enhancements have been implemented in ORAS4 with respect to the former product, such as model bias correction. For more thorough information on the data features and specifications, see Balmaseda et al. [20] and Balmaseda et al. [21]. Moreover, to explore the explanation of the NECC variations east of the dateline, we utilized the Ocean Reanalysis System 5's (ORAS5's) $20^{\circ} \mathrm{C}$ isotherm depth from ECMWF. The $20^{\circ} \mathrm{C}$ isotherm depth's spatial and temporal resolutions are $1^{\circ}$ and monthly, respectively [22].

We also used the ECMWF Reanalysis v5 (ERA5) surface wind dataset over the Pacific Ocean, provided by the Copernicus Climate Change Service (C3S), to analyze the wind trend during the EP and $\mathrm{CP}$ of El Niño. By replacing ERA-Interim reanalysis, the data quality of the ERA5 reanalysis improved. The latitude and longitude grid resolution of these data is a $0.25^{\circ} \times 0.25^{\circ}$ grid. The outstanding details of the ERA5 data information and specifications were provided by Hersbach et al. [23] and Molina et al. [24]. The wind data were converted to zonal $\left(\tau_{x}\right)$ and meridional $\left(\tau_{y}\right)$ wind stress components, obtained using Equations (1) and (2), taken from Kok et al. [25]:

$$
\begin{aligned}
& \tau_{x}=\rho_{a} C_{d}\left(u^{2}+v^{2}\right)^{1 / 2} u \\
& \tau_{y}=\rho_{a} C_{d}\left(u^{2}+v^{2}\right)^{1 / 2} v
\end{aligned}
$$

where $\rho_{a}$ is the air density $\left(1.2 \mathrm{~kg} / \mathrm{m}^{3}\right)$; the drag coefficient, $C_{d}$, equaled $1.3 \times 10^{-3}$, while $u$ indicates the zonal component of wind, and $v$ represents the meridional component. Additionally, Sverdrup Balance was also estimated to investigate the effects of local wind stress in NECC variability. We determined the Sverdrup zonal transport using the following formula [26]:

$$
U=-\frac{1}{\beta} \int\left(\frac{\partial \tau_{y}}{\partial x}-\frac{\partial \tau_{x}}{\partial y}\right) d x
$$

The National Oceanic and Atmospheric Administration (NOAA) optimum interpolation sea surface temperature (OISST) v2 products were used in this work to compare the horizontal distribution of the SST anomaly in the Pacific Ocean during the different types of El Niño [27]. This data analysis employed a monthly and $1^{\circ}$ spatial resolution, which was constructed by combining numerous observations on a regular grid, such as floating devices, satellites, and ship surveys. The Oceanic Niño Index (ONI), expressed by the running 3-month mean SST anomaly in the Niño 3.4 region (which is approximately $5^{\circ} \mathrm{N}$ to $5^{\circ} \mathrm{S}, 170^{\circ} \mathrm{W}$ to $120^{\circ} \mathrm{W}$ ), was the significant indicator used to observe the variability of $\mathrm{El}$ 
Niño and La Niña events. The National Oceanic and Atmospheric Administration (NOAA) supplied this index, which was operated to determine the intensity of the El Niño event. We only observed moderate to very strong events, which were classified as follows: 1.0 to 1.4 for a moderate event, 1.5 to 1.9 for a strong event, and $\geq 2.0$ for a very strong event.

Employing wide-area and long-time-series data for observation, the empirical orthogonal function (EOF) appeared to be a tool of convenience for performing the analysis and has been commonly used to extract the dominant variance [28,29]. The EOF analysis produced a pair of dominant spatial patterns along with the corresponding principal component (PC) that displayed the temporal pattern. To begin, we eliminated the annual cycle from the data and then computed the first three EOFs for JJA, SON, DJF, and MAM of the zonal component of the surface current to identify the dominant modes of the NECC variability in the summer, fall, winter, and spring, respectively, over 40 years.

\section{Results}

We averaged the zonal velocity component of the ORAS4 to the east of the dateline in the Pacific Ocean, which we display in Figure 1a. The eastward-flowing NECC was denoted by the positive value of zonal velocity, which laid between the latitudes of $4^{\circ} \mathrm{N}$ and $10^{\circ} \mathrm{N}$. This region represented the mean pathway of the NECC, which looked uniform to the east of the dateline. Several earlier investigations reported that the NECC pathway was broader to the west of the dateline and narrower to the east of the dateline [8,9]. Moreover, the NECC's average eastward velocity attained its peak between $160^{\circ} \mathrm{W}$ and $130^{\circ} \mathrm{W}$.
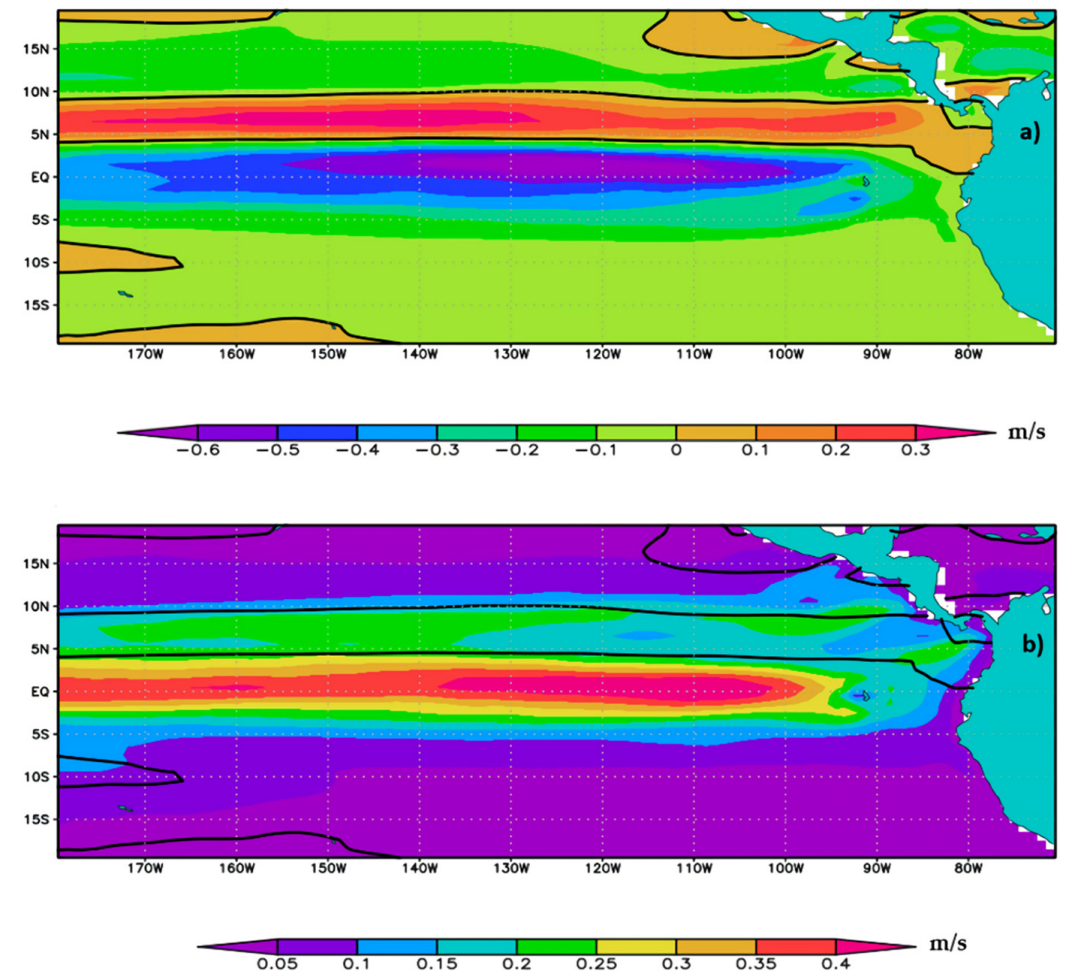

Figure 1. Mean map of (a) zonal velocity of ORAS4 surface current and (b) the corresponding standard deviation, calculated over the period of 1978 to 2017.

The standard deviation of the zonal velocity from the ECMWF ORAS4 data is presented in Figure 1b, which was computed from January 1978 to December 2017. A large standard deviation was observed just south of the NECC, widely known as south equatorial current (SEC); the standard deviation over the 40 -year period was $0.4 \mathrm{~m} \mathrm{~s}^{-1}$. At the same time, the standard deviation in the NECC region was lower (less than $0.25 \mathrm{~m} \mathrm{~s}^{-1}$ ). This result suggested that in order to reduce the interference of the SEC signal, the EOF analysis in the next figure would cover the region between the latitude of $3.5^{\circ} \mathrm{N}$ to $11.5^{\circ} \mathrm{N}$. 


\subsection{EOF Analysis}

The EOF spatial patterns of the NECC for the boreal summer (only the results of the first two EOF modes) are shown in Figure 2. The accumulative explained variance was $62.4 \%$ by the first two modes. The first mode (EOF1) explained $41.6 \%$ of the total variance. This mode displayed a positive signal region throughout $3.5^{\circ} \mathrm{N}$ to $8^{\circ} \mathrm{N}$ that was centered in the central Pacific. In the eastern Pacific, this signal gradually shifted northward to $9^{\circ} \mathrm{N}$. The related time series (PC1) showed a strong association between the NECC and ENSO events. Almost every El Niño or La Niña event caused the NECC to strengthen or weaken, as evidenced by the positive or negative phase, respectively, in Figure 2B. A slight difference was found by comparing the EP and CP types of El Niño. For the period of 1978 to 2017, five events of El Niño of the EP type were identified and are shown in Table 1. By contrast, four events were recorded in the case of the CP type [30,31]. From the PC1, the EP El Niño frequently produced a more major positive phase than the CP-El Niño (except for the 1986/1987 event), implying that the NECC was more powerful during the EP type. Furthermore, the second mode (EOF2) explained $20.8 \%$ of the total observations. Spatially, the positive signal was found further southward than that of the first mode (EOF1), with the variability maxima located in the area between $150^{\circ} \mathrm{W}$ and $130^{\circ} \mathrm{W}$. The corresponding PC2 showed less of a relationship to the ENSO event.

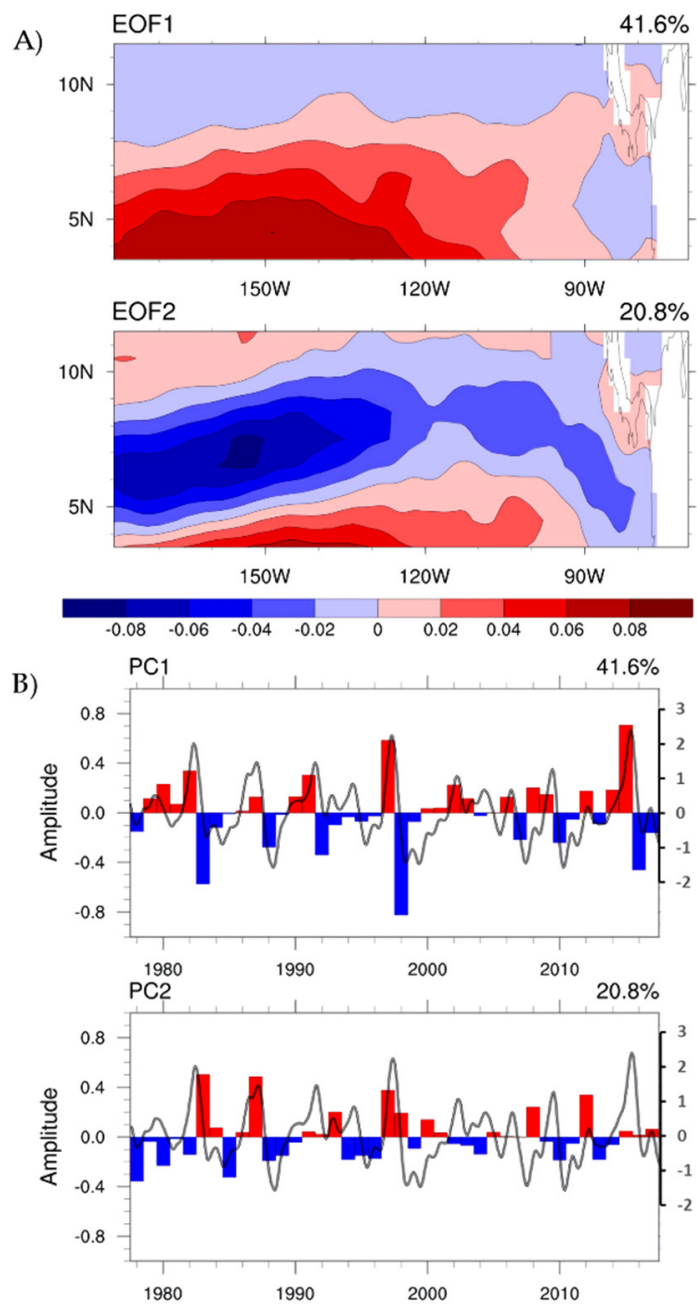

Figure 2. Two leading EOF analyses of the zonal component of surface current for summer (JJA): (A) spatial pattern and (B) time series of the principal component superimposed with 6 months low-pass filtered NIÑO 3.4 index. Red and blue bars represented the NECC's strengthening and weakening, respectively. 
Table 1. El Niño events ranging from moderate to very strong from 1978 to 2017 and their classification based on the Niño methods.

\begin{tabular}{cccc}
\hline Type & Moderate & Strong & Very Strong \\
\hline CP El Niño & $1994 / 1995,2002 / 2003,2009 / 2010$ & $1987 / 1988$ & - \\
\hline EP El Niño & $1986 / 1987$ & $1991 / 1992$ & $1982 / 1983,1997 / 1998,2015 / 2016$ \\
\hline
\end{tabular}

The first two leading EOF modes with their corresponding time series (PC) for fall $(\mathrm{SON})$ are plotted in Figure 3, which explained $63.7 \%$ and $9.2 \%$ of the observed variability, respectively. The first EOF pattern (EOF1) showed a similar pattern to that of the EOF1 for summer (Figure 2A), and the positive signal was found near the equator. From the corresponding PC1, we can see roughly that the variability was very much related to the ENSO event. Unlike the EOF1 for summer, the NECC's reaction to the EP and CP types of El Niño looked no different in this season. Every El Niño event produced a positive phase, while the La Niña produced a negative phase. Moreover, the second EOF2 pattern showed a negative signal that seemed to merge with the positive signal in the north. The associated PC time series (PC2) exhibited that the variability after the 2000s produced the negative phase more.

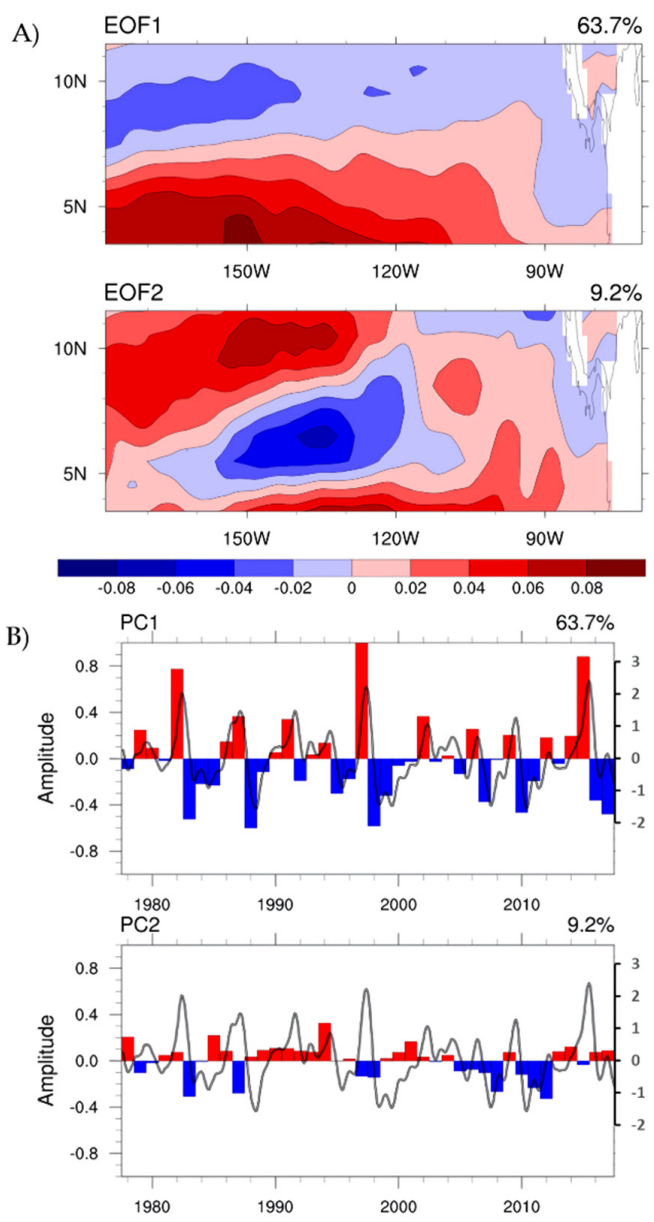

Figure 3. Same as Figure 2, but for fall (SON): (A) spatial pattern and (B) time series of the principal component superimposed with 6 months low-pass filtered NIÑO 3.4 index. Red and blue bars represented the NECC's strengthening and weakening, respectively.

Figure 4 shows the first two EOF modes of winter (DJF), which explained 30.3\% and $11.8 \%$ of the total variance of the zonal velocity of the ORAS4 surface current. Spatially, the first leading EOF (EOF1) was maximal near the equator and was centered between 
the longitudes of $150^{\circ} \mathrm{W}$ and $120^{\circ} \mathrm{W}$. In the eastern Pacific, the positive signal was found around $9^{\circ} \mathrm{N}$, similar to the pattern that was shown in the EOF1 for summer. The corresponding PC1 mode indicated a strong relationship to the cold event, portrayed by the negative phase that consistently appeared in each La Niña year. Meanwhile, in relation to the El Niño, the positive phase arose in the years 1987/1988, 1994/1995, 2002/2003, 2009/2010,1986/1987, 1991/1992, and 2015/2016, of which the last three belonged to the EP type of El Niño and the remainder were CP type. For the winter, these results implied that the CP El Niño generated a relatively stronger NECC than the EP-El Niño. This suggestion is of particular interest since the presence of three EP El Niño events was linked to the intensification of NECC. Nevertheless, Hu et al. [17], Paek et al. [32], and Zhang et al. [33] reported that the El Niño event of 1991/1992 and 2015/2016 were classified as a combination of both $\mathrm{CP}$ and EP events, commonly known as the MIX El Niño type, with a wide spread of the SST anomaly to the east of the dateline in the Pacific Ocean. Perhaps for this reason, they appeared as positive phases in the PC1 variability. By contrast, for the 1986/1987 event, Chen and Li [34] reported that the EP El Niño of 1986/1987 was a special EP El Niño that generated strong westerly wind events in the winter and re-evolved into a subsequent El Niño event. By contrast, the second leading mode (EOF2) showed a positive signal further northward. The related time series (PC2) exhibited decreased year-to-year variability beginning in the early 2000s. This result implies that the NECC has undergone weakening in the last two decades. Furthermore, the relationship with the ENSO event was much weaker in PC2.

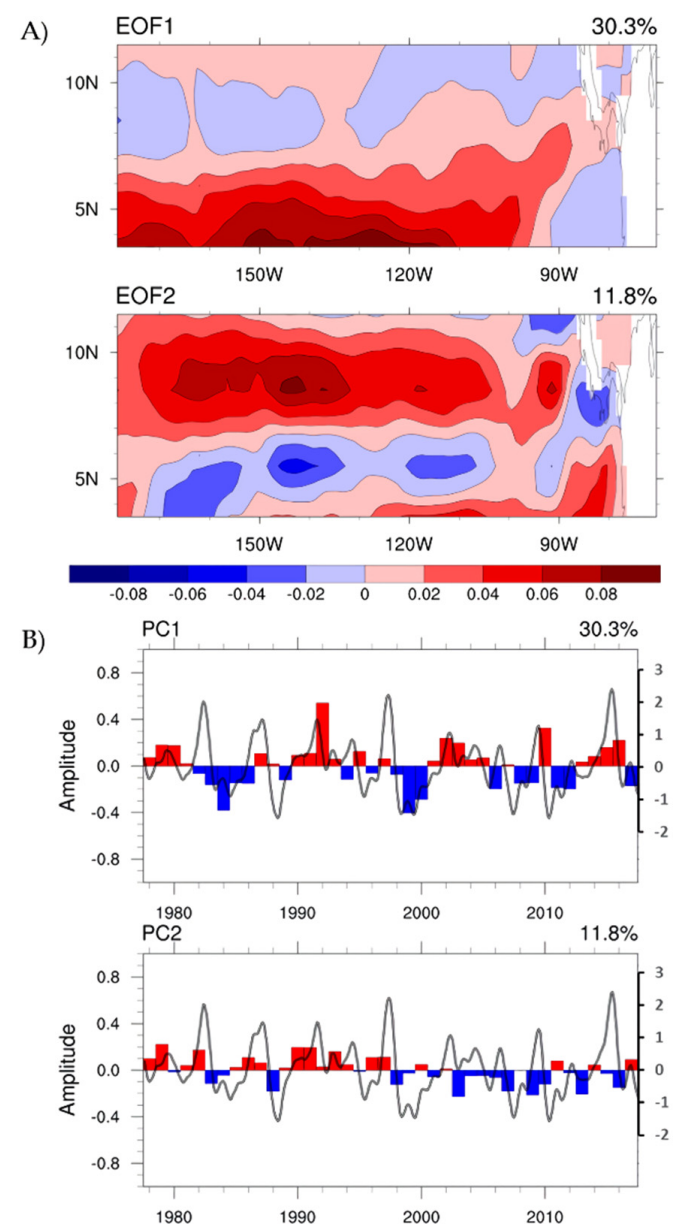

Figure 4. Same as Figure 2, but for winter (DJF): (A) spatial pattern and (B) time series of the principal component superimposed with 6 months low-pass filtered NIÑO 3.4 index. Red and blue bars represented the NECC's strengthening and weakening, respectively. 
As shown in Figure 5, the spring EOF1 pattern (MAM) explained 51.1\% of the overall variance. The EOF1 exhibited a dipole spatial pattern, with the positive signal centered at a latitude of $\sim 4.5^{\circ} \mathrm{N}$. In the time series, the corresponding PC1 was highly correlated with the EP type of El Niño event. When the EP and MIX types started to develop in the springs of 1982, 1991, 1997, and 2015, they produced an obvious positive phase. The CP type, on the other hand, resulted in a negative phase and a minor positive phase. This result suggests that the EP and MIX El Niño types produced a more powerful NECC than the CP El Niño. On the other hand, in the second EOF (EOF2) mode, the zonal velocities showed a positive-negative-positive pattern with variability maxima north of $3.5^{\circ} \mathrm{N}$, which only accounted for $10.5 \%$ of the total variance. The related time series PC2 denoted no significant relationship with the ENSO event.

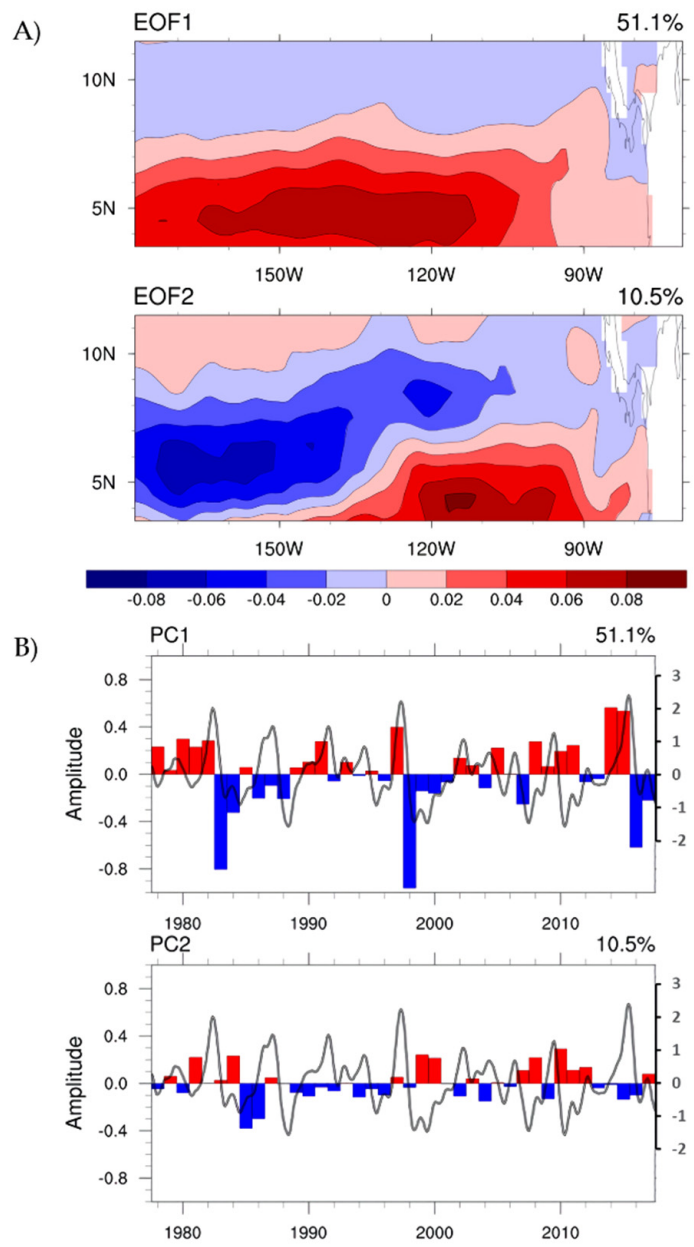

Figure 5. Same as Figure 2, but for spring (MAM): (A) spatial pattern and (B) time series of the principal component superimposed with 6 months low-pass filtered NIÑO 3.4 index. Red and blue bars represented the NECC's strengthening and weakening, respectively.

\subsection{Meridional Shifting of the NECC}

Next, to explore the variability of the NECC to the east of the dateline over 40 years, we plotted the zonal component as time against latitude using the meridional line at $150^{\circ}$ $\mathrm{W}$ as a reference (Figure 6). The positive value was considered the eastward flow, showing variations in the NECC's path. Seasonally, an equatorward shift was observed to occur frequently in mid-winter to spring, but this event was absent in certain years. An El Niño event is capable of inhibiting an equatorward shift of the NECC only if certain criteria are met. 

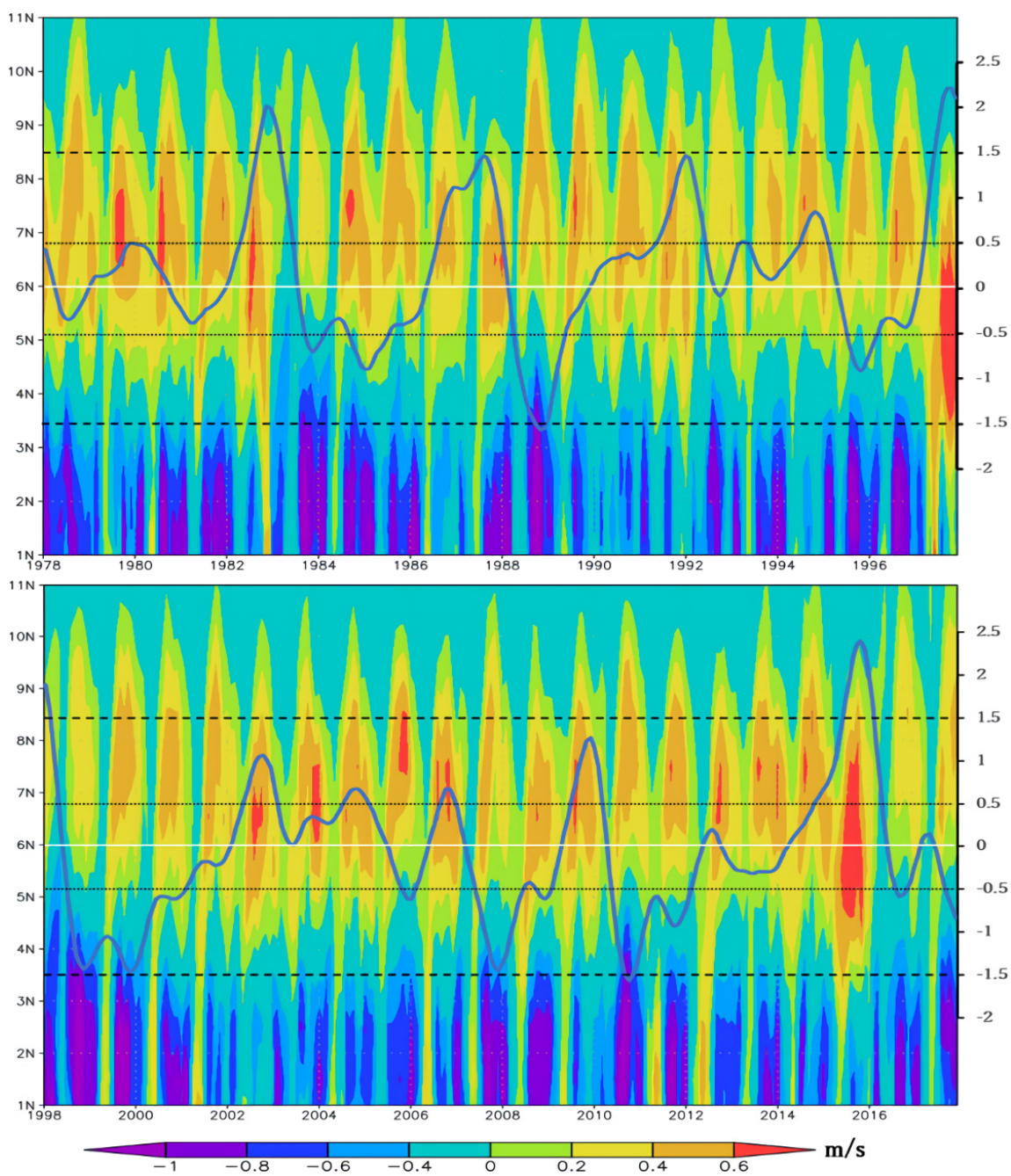

Figure 6. Latitude-time diagram of the zonal component of surface current at the meridional line $150^{\circ} \mathrm{W}, 6$-month low-pass filtered NIÑO 3.4 index overlaid (blue line). Upper panel for January 1978 to December 1997 and lower panel for January 1998 to December 2017.

The absence of an equatorward shift corresponded to moderate to very strong El Niño events, but this is not the only requirement to interfere with such a shift. The current article classified El Niño event into three types: EP, CP, and MIX types, as suggested by a number of prior studies [14-17,33]; however, only two forms of El Niño may prevent the NECC so that it does not shift toward the equator, namely the CP and MIX types. Over 40 years, the CP El Niño and MIX El Niño events occurred in the years 1987/1988, 1994/1995, 2002/2003, 2009/2010, 1991/1992, and 2015/2016. The equatorward shift did not take place during the stage of maturing of the events of the CP and MIX types. By contrast, the NECC still shifted toward the equator in the EP type, which was recorded in the year 1982/1983, 1986/1987, and 1997/1998. Furthermore, in the events of 1982/1983 and 1997/1998, which fell into the very strong El Niño category, the equatorward shift occurred earlier in the winter.

The investigation of the wind and SST distribution over the near-equatorial region of the Pacific is critical for a better understanding of the various patterns that formed during the three types of El Niño events. We averaged the components of wind stress and SST over the winter for each kind of El Niño, which are displayed in Figure 7. This figure depicts substantial variation in the distribution of SST and wind stress in the CP, MIX, and EP types of El Niño. All kinds of El Niño were characterized by a positive anomaly of the SST across the equatorial region of the Pacific, and the distinction was in the position of the highest positive anomaly of the SST $[14,16,17,33]$. The smallest magnitude of the 
SST anomaly occurred during the CP type, with the peak located near a longitude of $170^{\circ} \mathrm{W}$, accompanied by anomalously westerly wind stress in the southern part of the central equatorial region. As for the MIX El Niño, the highest anomaly of the SST was located around $20^{\circ}$ further east than that of the CP type. Strong northerly and westerly wind stress was found in the region between $180^{\circ} \mathrm{E}$ and $150^{\circ} \mathrm{W}$. Moreover, the area of maximum SSTA for the EP El Niño was larger and farther east than those of the CP and MIX types, followed by a significant anomaly of northerly and westerly wind stress in the central-eastern equatorial Pacific. This result also suggests that under all forms of El Niño, the trade wind over the equatorial Pacific was weaker.
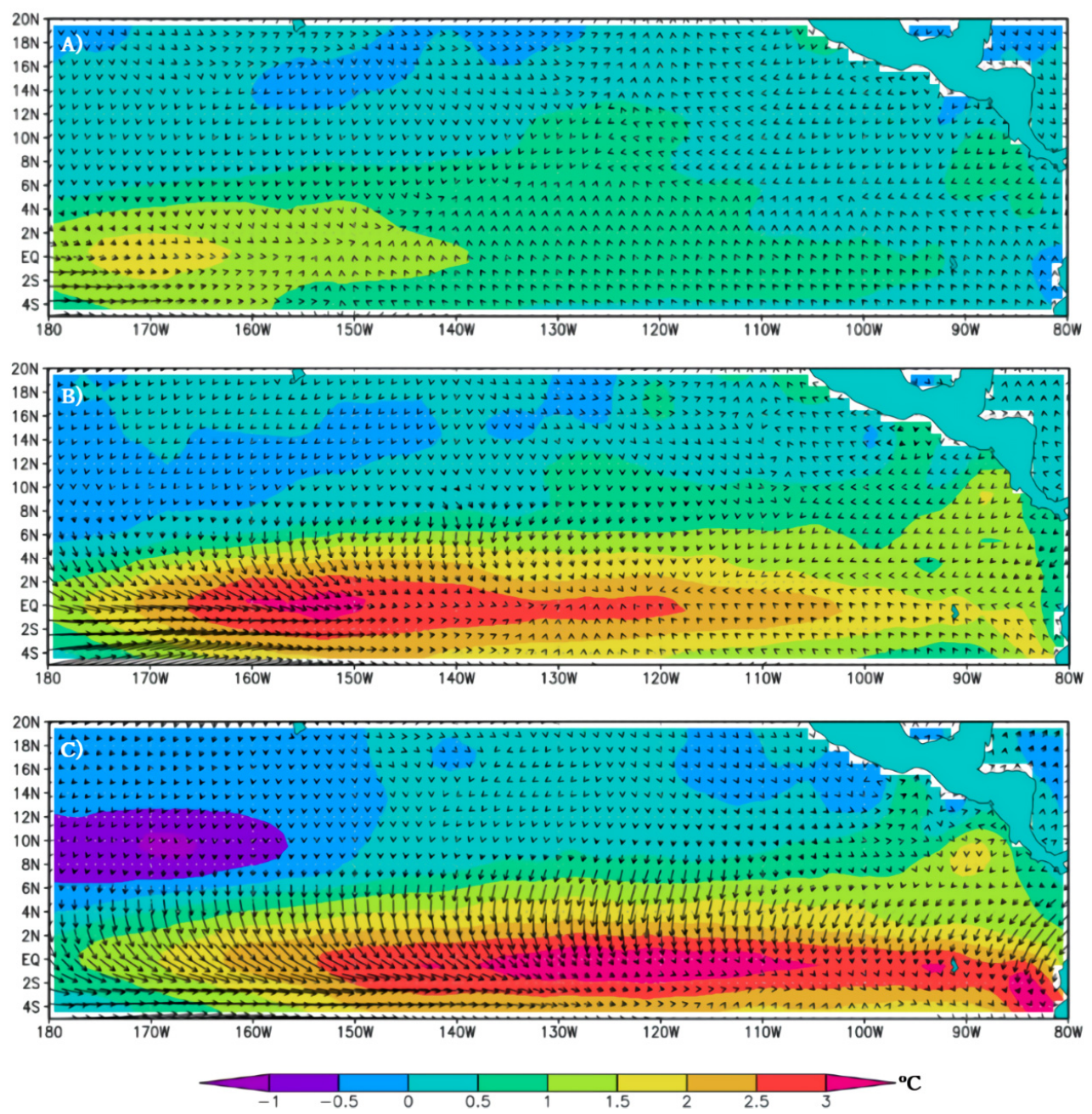

Figure 7. The mean surface wind stress anomaly (vectors) with SST field (shaded) to the east of the dateline during the winter of El Niño events of the (A) CP type, (B) MIX type, and (C) EP type.

Furthermore, to examine the relationship between wind stress distribution and NECC variations, we computed the curl of the wind stress using the zonal and meridional components, then performed Sverdrup balance (SB) analyses. Based on the ECMWF $0.25^{\circ}$ monthly wind component of the ERA5, Figure 8 depicts a comparison of the average winter SB in each kind of El Niño event. Significant differences were observed when comparing eastward transport among the $\mathrm{CP}, \mathrm{MIX}$, and EP types, which is represented by a positive value of SB. The eastward transport near 0 latitude for the CP El Niño was positioned at $\sim 4^{\circ} \mathrm{N}$ in the central-eastern Pacific and proceeded northward at a latitude of $\sim 7^{\circ} \mathrm{N}$ as it approached land. The MIX El Niño's eastward transport was found at $1^{\circ} \mathrm{N}$ in the central Pacific and progressively migrated northward at a latitude of $3^{\circ} \mathrm{N}$ in the eastern Pacific, while it laid at $\sim 7^{\circ} \mathrm{N}$ in the easternmost Pacific Ocean. As for the EP El Niño, this eastward 
transport was migrated to the south of $\sim 1^{\circ} \mathrm{S}$ in the central Pacific Ocean and stayed at $\sim 2^{\circ}$ $\mathrm{N}$ in the eastern Pacific. Moreover, as happened in the CP and MIX types, the eastward-flow transport was similarly positioned around $\sim 7^{\circ} \mathrm{N}$ latitude in the easternmost Pacific Ocean. Thus, this SB analysis revealed the meridional shift of the eastward-flowing NECC, which indicated good agreement with the analysis of the NECC variations in Figure 6.

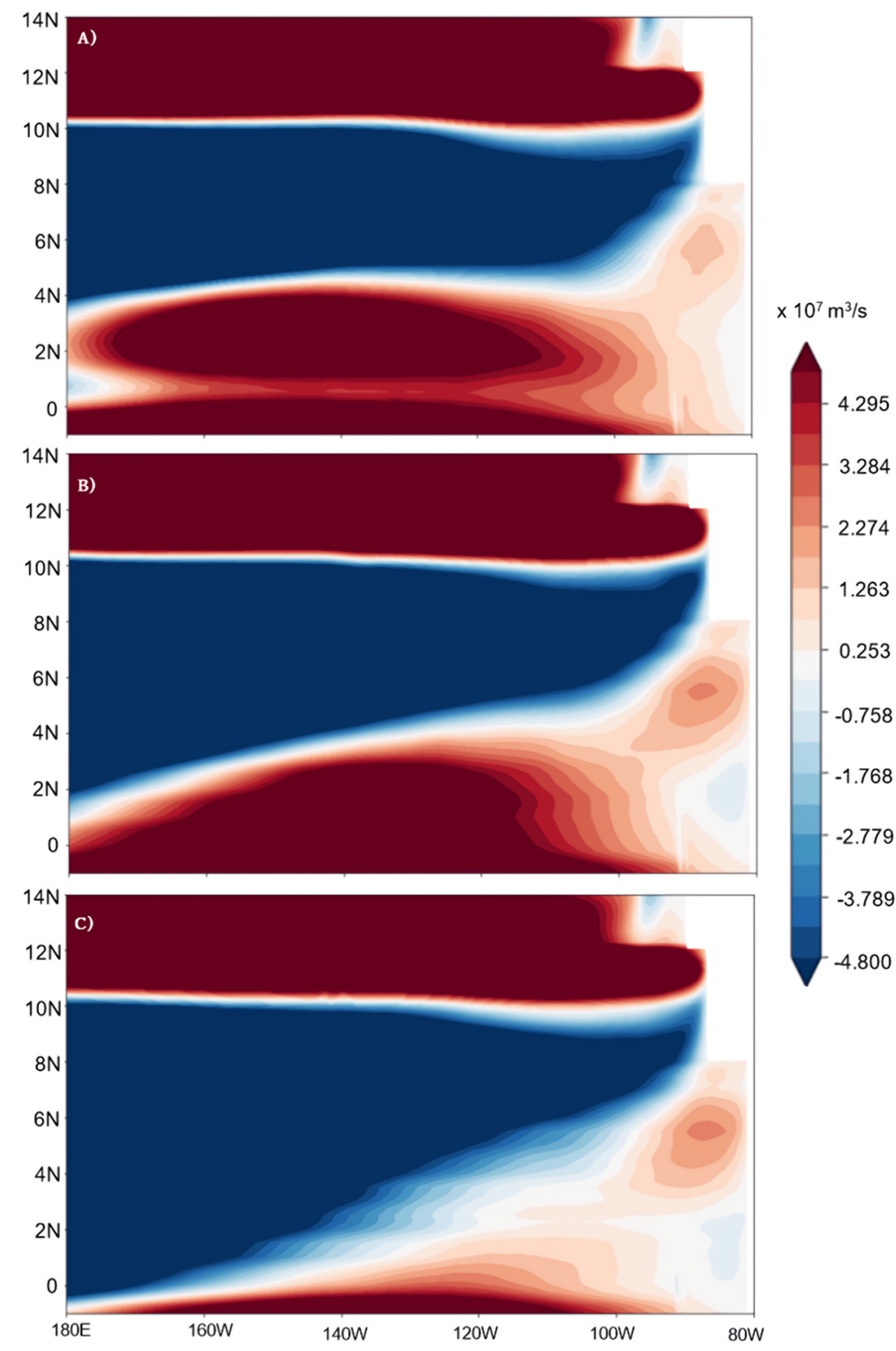

Figure 8. Average of Sverdrup balance (SB) in $10^{7} \mathrm{~m}^{3} / \mathrm{s}$ during the winter of El Niño events of the (A) CP type, (B) MIX type, and (C) EP type. The colors red and blue represent east and west transport flow, respectively.

\section{Discussion}

The current paper investigated the NECC variability to the east of the dateline, which was found to be closely associated with the ENSO event. We used the zonal velocity of surface current data derived from the ECMWF from 1978 to 2017 on a regular grid with a $1^{\circ} \times 1^{\circ}$ spatial resolution. We applied the EOF analysis to each season, which was broken down into the winter (December to February), spring (March to May), summer (June to August), and fall (September to November). Interestingly, the dominant seasonal pattern 
of NECC was obtained from this analysis. We also employed the SST data from NOAA and the ERA5 wind data from the ECMWF.

For all seasons, the EOF analysis revealed that the NECC showed a tendency to strengthen in El Niño, while it tended to weaken in La Niña. However, El Niño, categorized into the EP, $\mathrm{CP}$, and MIX types, produced a quite different impact on the NECC each season. For the spring and summer, which are frequently linked with the developing phase, the NECC was substantially more powerful during the EP and MIX types compared with the CP type. By contrast, the EP type weakened the NECC during the winter, which is often considered as the mature stage, whereas it became stronger during the $\mathrm{CP}$ and MIX types. Unlike other seasons, the relatively equal impact of the EP and CP types of El Niño on the NECC was observed during the fall season. The NECC indicated a tendency to strengthen in all forms of El Niño. The fluctuation of isotherm depth at $20^{\circ}$ (D20) could have caused this NECC variability around the Pacific Ocean (Figures 9 and 10), which was influenced by the wind stress distribution [35]. Through the Ekman transport process, the summer of the EP El Niño raised the thermocline in the northwestern Pacific while lowering it in the eastern Pacific, producing a meridional gradient of sea level, and resulted in a more robust NECC (Figure 9A). During the CP El Niño, on the other hand, the decreased sea level gradient between the northwestern and east Pacific led to a small strengthening of the NECC (Figure 9B). As the CP El Niño entered its mature phase, the shoaling of the thermocline occurred in the northwestern Pacific and then increased the meridional gradient of sea level. As a result, the NECC tended to strengthen (Figure 10B). Moreover, for the EP type, the thermocline shoaling (deepening) took place along the western to the central (eastern) Pacific Ocean, causing the NECC to weaken (Figure 10A). This weaker NECC during the EP El Niño's winter was unexpected and has never been reported in previous studies. Additionally, the thermocline, which occurred in the western Pacific to the east of the dateline $\left(160^{\circ} \mathrm{W}\right)$, was raised in January 1983 and 1998 (Figure 11). In consequence, the NECC became weaker. However, its exact mechanism is still undetermined; therefore, we leave for further research the investigation of how the winter of EP El Niño could generate a weaker NECC.

\section{A) Summer EP-El Nino}

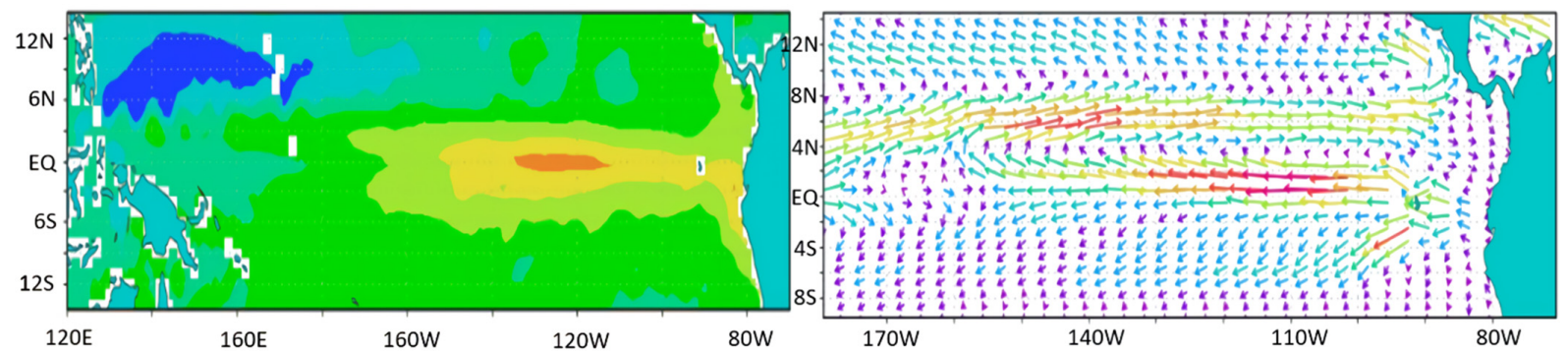

B) Summer CP-El Nino

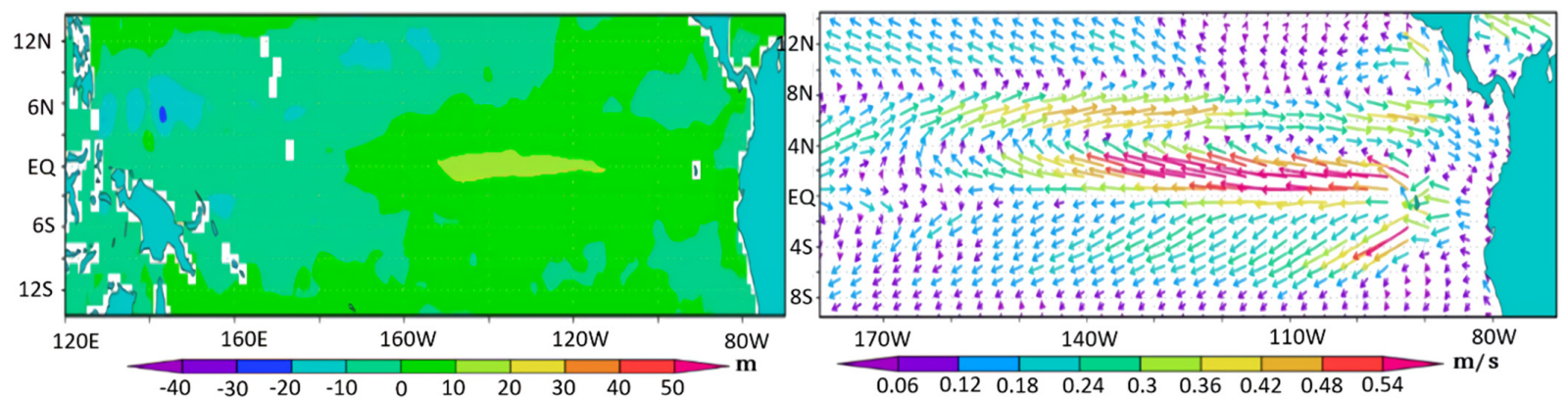

Figure 9. Composite maps of $20^{\circ} \mathrm{C}$ isotherm depth (D20) anomalies (left panel) and ocean surface current (right panel) for the summer from (A) the EP El Niño and (B) CP El Niño. Negative (Positive) D20 anomalies denote shoaling (deepening). 


\section{A) Winter EP-El Nino}
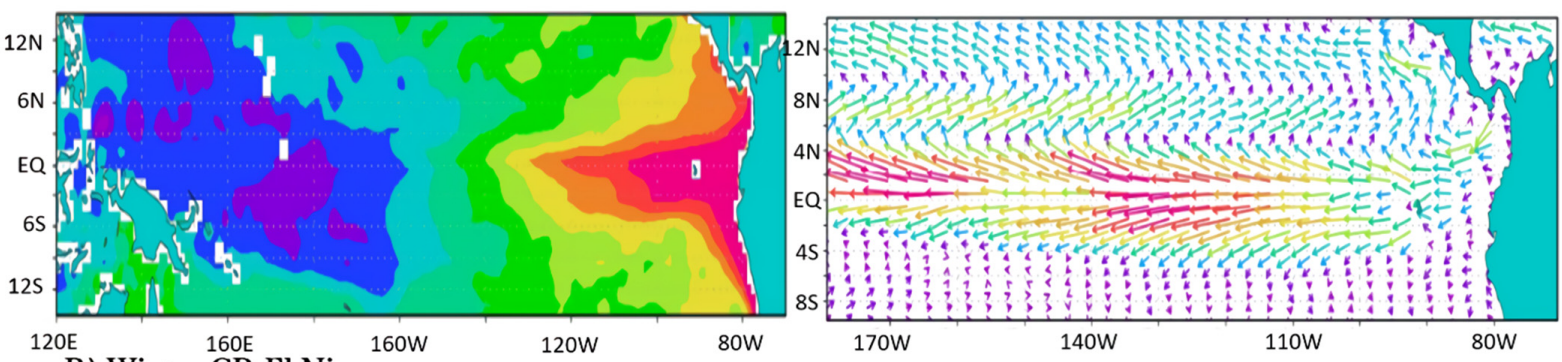

B) Winter CP-El Nino
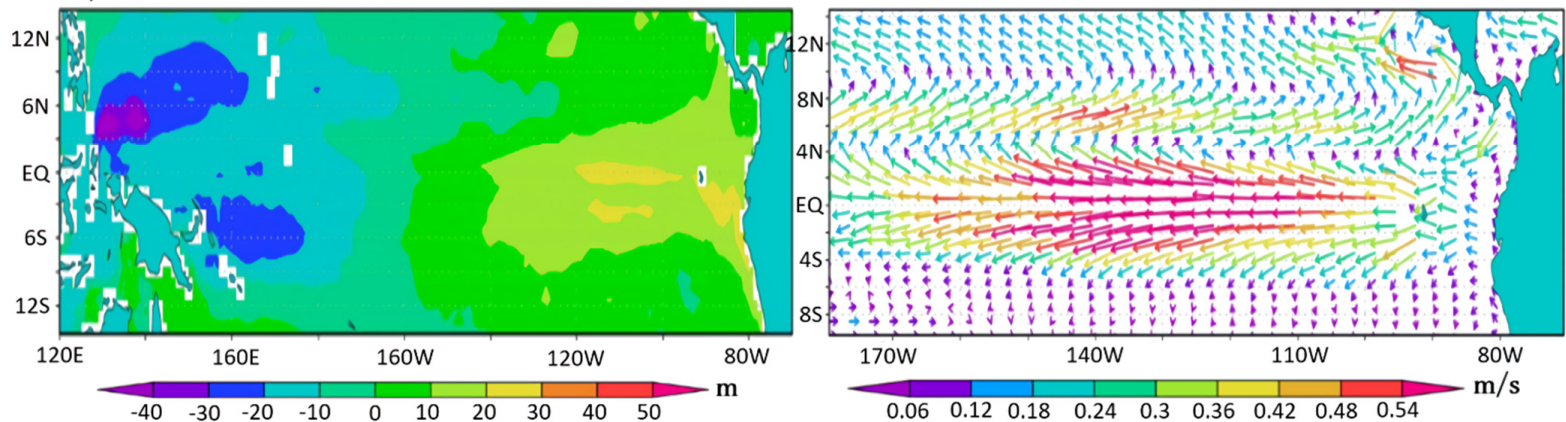

Figure 10. Same as Figure 9, but for winter from (A) the EP El Niño and (B) CP El Niño. Negative (Positive) D20 anomalies denote shoaling (deepening).

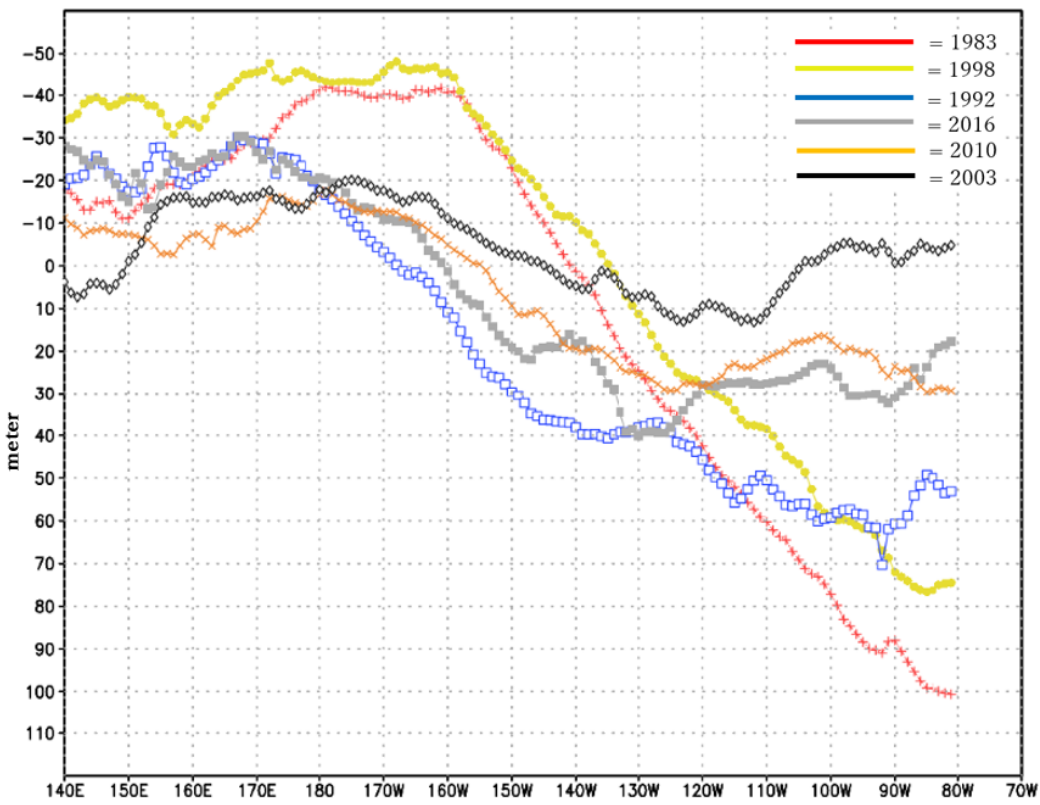

Figure 11. Equatorial Pacific D20 anomaly for January. Each type of El Niño was represented by two events; 1983 and 1998 representing EP type; 1992 and 2016 representing MIX type; 2003 and 2010 representing CP type.

With regard to the NECC's meridional shifting, the seasonal southward shift occurred between mid-winter to spring, then traveled to the north in the second half of the year. This result is consistent with Shin and Qiu [8]. We also found that the southward shift was missing in several El Niño years, specifically the CP and MIX El Niño. During these events, the absence of the southward shift in the CP and MIX El Niño agreed well with the SB pattern. From the SB analysis generated by local wind stress curl, the zero contour of the eastward transport near the equator was located between $0^{\circ}$ and $1^{\circ} \mathrm{S}$ during the EP El Niño. Meanwhile, the zero contour migrated to the north of $3^{\circ} \mathrm{N}$ and $4^{\circ} \mathrm{N}$ for the 
EP and MIX El Niño types, respectively. Prior studies, however, have shown the NECC's southward movement during the EP El Niño [8,12].

\section{Conclusions}

In the present paper, reanalysis data examined the NECC variations east of the dateline and how they responded to the three types of El Niño. Our findings led us to the following conclusions:

(1) The NECC was considerably stronger during the EP and MIX El Niño than during the CP El Niño for the spring and summer, which are frequently linked with the development period. During the fall, the three types of El Niño did not differ significantly in terms of affecting the NECC's variations. These stronger and weaker NECCs east of the dateline are influenced by the thermocline depth oscillations across the Pacific Ocean.

(2) Going through a mature phase, which is generally in the winter, the NECC during the EP El Niño was weaker than the NECC during the CP and MIX El Niño. This finding provides a new suggestion for future investigation because it has not been documented in previous studies.

(3) The NECC shift to the south is absent during the CP and MIX El Niño events because of the local wind stress distribution. This southward shift, however, remained apparent during the EP El Niño.

Based on the results of this study, we give a fresh suggestion regarding the influence of the three types of El Niño on the NECC variations east of the dateline for each season. The NECC appeared to react differently in each season to the three types of El Nino. After thorough research, we discovered that the NECC has a propensity to steadily strengthen from the development to the mature phase of MIX El Niño events, which has not been accomplished before by previous research. Furthermore, the conclusions of this study enable further investigation into the behavior of other ocean circulations in the Pacific Ocean in response to the MIX El Niño event, for which little information is available.

Author Contributions: Conceptualization, Y.J.W. and U.J.W.; methodology, Y.J.W. and Y.H.; software, Y.J.W.; validation, Y.J.W. and Y.H.; formal analysis, Y.J.W. and Y.H.; investigation, Y.J.W. and Y.H.; resources, Y.J.W. and U.J.W.; data curation, Y.J.W. and U.J.W.; writing-original draft preparation, Y.J.W.; writing-review and editing, Y.J.W. and Y.H.; visualization, Y.J.W.; supervision, Y.H.; project administration, Y.H.; funding acquisition, Y.H. All authors have read and agreed to the published version of the manuscript.

Funding: This study was financially supported by a Grant-in-Aid for Scientific Research (C-2) from the Ministry of Education, Culture, Sports, Science, and Technology of Japan (20K04708).

Institutional Review Board Statement: Not applicable.

Informed Consent Statement: Not applicable.

Data Availability Statement: All of the study's data is available for free download at http: / /apdrc. soest.hawaii.edu/las/v6/dataset (accessed on 30 July 2021).

Acknowledgments: The first author at The University of the Ryukyus Department of Physics and Earth Sciences who is funded by the Japanese Ministry of Education, Culture, Sports, Science and Technology (MEXT).

Conflicts of Interest: The authors declare no conflict of interest.

\section{References}

1. Zhao, J.; Li, Y.; Wang, F. Seasonal Variation of the Surface North Equatorial Countercurrent (NECC) in the Western Pacific Ocean. Chin. J. Oceanol. Limnol. 2016, 34, 1332-1346. [CrossRef]

2. Wijaya, Y.J.; Hisaki, Y. Differences in the reaction of north equatorial countercurrent to the developing and mature phase of ENSO events in the western Pacific Ocean. Climate 2021, 9, 57. [CrossRef]

3. Johnson, G.C.; Sloyan, B.M.; Kessler, W.S.; McTaggart, K.E. Direct measurements of upper ocean currents and water properties across the tropical Pacific during the 1990s. Prog. Oceanogr. 2002, 52, 31-61. [CrossRef] 
4. Hsin, Y.-C. Trends of the pathways and intensities of surface equatorial current system in the north Pacific Ocean. J. Clim. 2016, 29, 6693-6710. [CrossRef]

5. Donguy, J.R.; Meyers, G. Mean annual variation of transport of major currents in the tropical Pacific Ocean. Deep Sea Res. Part I Oceanogr. Res. Pap. 1996, 43, 1105-1122. [CrossRef]

6. Webb, D.J. On the role of the North Equatorial Counter Current during a strong El Niño. Ocean Sci. 2017, 14, 633-660. [CrossRef]

7. Seo, I.; Lee, Y.I.; Kim, W.; Yoo, C.M.; Hyeong, K. Movement of the intertropical convergence zone during the mid-pleistocene transition and the response of atmospheric and surface ocean circulations in the central equatorial Pacific. Geocherm. Geophys. Geosyst. 2015, 16, 3973-3981. [CrossRef]

8. Hsin, Y.-C.; Qiu, B. The impact of Eastern-Pacific versus Central-Pacific El Niños on the North Equatorial Countercurrent in the Pacific Ocean. J. Geophys. Res. 2012, 117, C11017. [CrossRef]

9. Zhao, J.; Li, Y.; Wang, F. Dynamical responses of the west Pacific North Equatorial Countercurrent (NECC) system to El Niño events. J. Geophys. Res. Ocean. 2013, 118, 2828-2844. [CrossRef]

10. Wang, L.-C.; Wu, C.-R. Contrasting the Flow Patterns in the Equatorial Pacific between Two Types of El Niño. Atmosphere-Ocean 2013, 51, 60-74. [CrossRef]

11. Chen, X.; Qiu, B.; Du, Y.; Chen, S.; Qi, Y. Interannual and interdecadal variability of the North Equatorial Countercurrent in the Western Pacific. J. Geophys. Res. Oceans. 2016, 121, 7743-7758. [CrossRef]

12. Tan, S.; Zhou, H. The observed impacts of the two types of El Niño on the North Equatorial Countercurrent in the Pacific Ocean. Geophys. Res. Lett. 2018, 45, 10493-10500. [CrossRef]

13. Ashok, K.; Behera, S.K.; Rao, S.A.; Weng, H.; Yamagata, T. El Niño Modoki and its possible teleconnection. J. Geophys. Res. 2007, 112, C11007. [CrossRef]

14. Kug, J.-S.; Jin, F.-F.; An, S.-I. Two types of El Niño events: Cold tongue El Niño and warm pool El Niño. J. Clim. 2009, 22, 1499-1515. [CrossRef]

15. Yeh, S.-W.; Kug, J.-S.; Dewitte, B.; Kwon, M.-H.; Kirtman, B.-P.; Jin, F.-F. El Niño in a changing climate. Nature 2009, 461, 511-514. [CrossRef] [PubMed]

16. Kao, H.-Y.; Yu, J.-Y. Contrasting eastern-Pacific and central-Pacific types of ENSO. J. Clim. 2009, 22, 615-632. [CrossRef]

17. $\mathrm{Hu}, \mathrm{X}$.; Yang, S.; Cai, M. Contrasting the eastern Pacific El Niño and the central Pacific El Niño: Process-based feedback attribution. Clim. Dyn. 2016, 47, 2413-2424. [CrossRef]

18. Wen, N.; Liu, Z.; Li, L. Direct ENSO impact on East Asian summer precipitation in the developing summer. Clim. Dyn. 2018, 52, 6799-6815. [CrossRef]

19. Wu, B.; Zhou, T.; Li, T. Contrast of Rainfall-SST Relationship in the Western Pacific between the ENSO-Developing and ENSO Decaying Summers. J. Clim. 2009, 22, 4398-4405. [CrossRef]

20. Balmaseda, M.A.; Mogensen, K.; Weaver, A.T. Evaluation of the ECMWF ocean reanalysis system ORAS4. Q. J. R. Meteorol. Soc. 2013, 139, 1132-1161. [CrossRef]

21. Balmaseda, M.A.; Trenberth, K.E.; Källén, E. Distinctive climate signals in reanalysis of global ocean heat content. Geophys. Res. Lett. 2013, 40, 1754-1759. [CrossRef]

22. Zuo, H.; Balmaseda, M.A.; Mogensen, K.; Tietsche, S. OCEAN5: The ECMWF Ocean Reanalysis System and Its Real-Time Analysis Component; Technical Report 823; ECMWF: Reading, UK, 2018. [CrossRef]

23. Hersbach, H.; Bell, B.; Berrisford, P.; Hirahara, S.; Horányi, A.; Muñoz-Sabater, J.; Nicolas, J.; Peubey, C.; Radu, R.; Schepers, D.; et al. The ERA5 global reanalysis. Q. J. R. Meteorol. Soc. 2020, 146, 1999-2049. [CrossRef]

24. Molina, O.M.; Gutiérrez, C.; Sánchez, E. Comparison of ERA5 surface wind speed climatologies over Europe with observations from the HadISD dataset. Int. J. Climatol. 2021, 41, 4864-4878. [CrossRef]

25. Kok, P.H.; Mohd Akhir, M.F.; Tangang, F.; Husain, M.L. Spatiotemporal trends in the southwest monsoon wind-driven upwelling in the southwestern part of the South China Sea. PLoS ONE 2017, 12, e0171979. [CrossRef]

26. Kessler, W.S.; Johnson, G.C.; Moore, D.W. Sverdrup and Nonlinear Dynamics of the Pacific Equatorial Currents. J. Phys. Oceanogr. 2003, 33, 994-1008. [CrossRef]

27. Reynolds, R.W.; Rayner, N.A.; Smith, T.M.; Stokes, D.C.; Wang, W. An improved in situ and satellite SST analysis for Climate. J. Clim. 2002, 15, 1609-1625. [CrossRef]

28. Björnsson, H.; Venegas, S. A Manual for EOF and SVD Analyses of Climate Data; McGill University, Department of Atmospheric and Oceanic Sciences and Centre for Climate and Global Change Research Tech. Rep.: Montréal, QC, Canada, 1997; 52p.

29. Hannachi, A.; Jolliffe, I.T.; Stephenson, D.B. Empirical orthogonal functions and related techniques in atmospheric science: A review. Int. J. Climatol. 2007, 27, 1119-1152. [CrossRef]

30. Yu, J.-Y.; Zou, Y.; Kim, S.T.; Lee, T. The changing impact of El Niño on US winter temperatures. Geophys. Res. Lett. 2012, 39 , L15702. [CrossRef]

31. Zhu, A.; Xu, H.; Deng, J.; Ma, J.; Li, S. El Niño-Southern Oscillation (ENSO) effect on interannual variability in spring aerosols over East Asia. Atmos. Chem. Phys. 2021, 21, 5919-5933. [CrossRef]

32. Paek, H.; Yu, J.-Y.; Qian, C. Why were the 2015/2016 and 1997/1998 extreme El Niños different? Geophys. Res. Lett. 2017, 44, 1848-1856. [CrossRef]

33. Zhang, Z.; Ren, B.; Zheng, J. A unified complex index to characterize two types of ENSO simultaneously. Sci. Rep. 2019, 9, 8373. [CrossRef] [PubMed] 
34. Chen, M.; Li, T. Why 1986 El Niño and 2005 La Niña evolved different form a typical El Niño and La Niña. Clim. Dyn. 2018, 51, 4309-4327. [CrossRef]

35. Xu, K.; Huang, R.X.; Wang, W.; Zhu, C.; Lu, R. Thermocline fluctuations in the equatorial Pacific Related to the two types of El Niño event. J. Clim. 2017, 30, 6611-6627. [CrossRef] 